\title{
IDENTIFIKASI STRUKTUR GEOLOGI BAWAH PERMUKAAN BERDASARKAN NILAI SUSEPTIBILLITAS MAGNETIK BATUAN DI LAUT SULAWESI
}

\author{
Dhea Intan Patya ${ }^{1 *}$, Dadi Rusdiana ${ }^{1}$, Catur Purwanto ${ }^{2}$, Nanang Dwi Ardi ${ }^{1}$ \\ ${ }^{1}$ Prodi Fisika, Universitas Pendidikan Indonesia,Bandung 40154 \\ ${ }^{2}$ Pusat Penelitian dan Pengembangan Geologi Kelautan, \\ Badan Litbang Kementrian Energi dan Sumber Daya Mineral, Bandung 40174 \\ *email :dheaip95@gmail.com
}

\begin{abstract}
ABSTRAK
Telah dilakukan penelitian dengan menggunakan metode magnetik untuk mengetahui struktur geologi bawah permukaan di sekitar Laut Sulawesi. Pengambilan data dilakukan dengan menggunakan seperangkat alat Proton Procession Magnetometer pada Kapal Geomarine III dengan total 22 lintasan. Pengolahan data dengan koreksi IGRF untuk mendapatkan anomali medan magnet total. Hasil dari interpretasi kualitatif maupun kuantitatif yaitu berupa variasi nilai intensitas magnet total sebesar $-450 \mathrm{nT}$ dari arah timur laut menuju ke barat daya sebesar $110 \mathrm{nT}$. Variasi nilai anomali intensitas magnet total merupakan parameter dalam menentukan nilai suseptibilitas batuan yang sangat berpengaruh terhadap struktur geologi bawah permukaan di sekitar Laut Sulawesi. Pengaruh geologi yang dihasilkan adalah berupa daerah penunjaman dan terdapat patahan atau sesar. Nilai suseptibilitas magnetik batuan pada struktur bawah permukaan di sekitar Laut Sulawesi di dominasi batuan beku jenis andesit dan basalt, dan batuan metamorf $(k=0,067833-0,065333$ SI).
\end{abstract}

Kata kunci : Metode Magnetik, Anomali Magnetik, Struktur Geologi, Suseptibilitas.

\section{ABSTRACT}

A research has been conducted to used magnetic method to know the subsurface structure around Sulawesi Sea. The data was collected using a set Proton Procession Magnetometer tools on Geomarine III ship with a total 22 trajectories. Processing data with IGRF correction to obtain total field magnetic anomaly. The result qualitative and quantitative interpretation is a variation of the total magnetic intensity of $-450 \mathrm{nT}$ from the northeast toward the southwest of $110 \mathrm{nT}$. Variation of total anomaly magnetic intensity is a parameter in determine the susceptibility rock have the effect to the subsurface geological structure around Sulawesi Sea. The results of geological effect are a subduction zone and a fault section. Magnetic suseptibility of rocks on the subsurface around Sulawesi Sea is dominated by igneous rock are andesit and basalt rock, and metamophic rocks $(k=0,067833$ SI -0,065333 SI).

Keywords : Magnetic Method,Magnetic Anomaly, Geology Structure, Susceptibility. 


\section{PENDAHULUAN}

Indonesia merupakan negara kepulauan yang letaknya pada pertemuan tiga lempeng besar dunia yang sangat aktif yaitu lempeng Eurasia, lempeng Pasifik, dan lempeng Indo-Australia, dan satu lempeng mikro yaitu lempeng mikro Filipina. Oleh karena itu, wilayah Indonesia baik di darat maupun di laut sangatlah rawan terhadap bencana alam seperti gempa-gempa tektonik sampai tsunami.

Pulau Sulawesi merupakan pulau yang terletak di zona pertemuan di antara tiga pergerakan lempeng Hindia-Australia. Pulau Sulawesi memiliki keadaan geologi yang sangat rawan dan sering terjaidnya gerakan dan benturan lempeng bumi sehingga menimbulkan fenomena geologi seperti gempa dan tsunami. Di utara Indonesia Timur, lempeng pasifik menabrak sisi utara Pulau Irian dan pulau-pulau di utara Maluku Pada bagian utara Pulau Sulawesi dan kawasan Laut Maluku.

Pulau Sulawesi dan sekitarnya, khususnya Sulawesi bagian utara merupakan salah satu margin aktif yang paling rumit dalam jangka waktu geologi, struktur, dan juga tektonik. Wilayah ini merupakan pusat pertemua tiga lempeng konvergen, karena interaksi tiga kerak bumi utama (lempeng) di masa Neogeon (Simandjuntak, 1992).

Daerah Sulawesi Utara yang letaknya baik di darat maupun di laut merupakan daerah yang dekat dengan sumber gempa bumi dan penyebab tsunami akibat proses tektonik. Daerah Sulawesi Utara terdapat sesar aktif yang menimbulkan munculnya fenomena geologi. Sumber gempa di Laut Sulawesi biasanya berasal dari penunjaman sublempeng Sulawesi Utara, lempeng Panggungan Mayu, dan lempeng Sangihe yang letaknya di sebelah timur Sulawesi Utara. Gempa yang terjadi di laut ini juga akan menimbulkan tsunami.

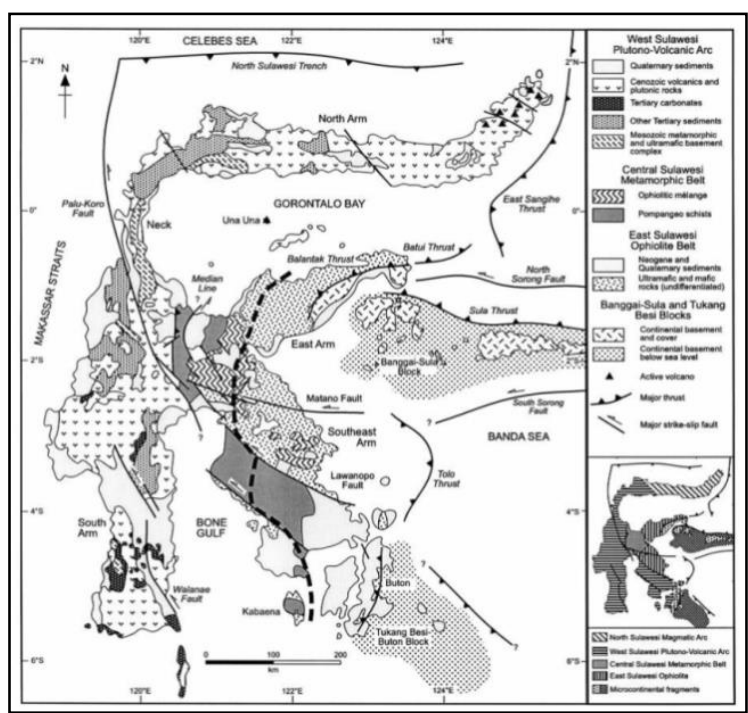

Gambar 1. Peta tektonik utama Pulau Sulawesi (Hall dan Wilson, 2000).

Wilayah yang ditinjau dalam penelitian ini adalah wilayah yang secara geografis termasuk ke dalam wilayah perairan Laut Sulawesi-Laut Maluku yang terletak pada koordinat 5,33'57" LU - 1,08'17" LU dan 126,35'29" BT - 122,25'47 BT.

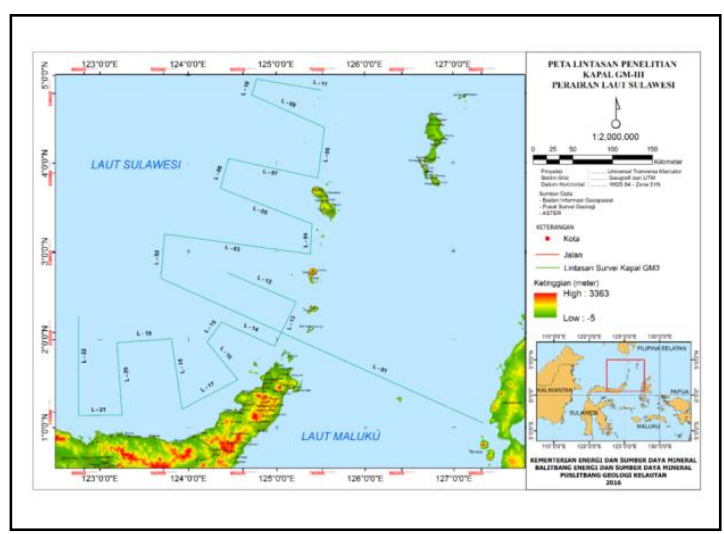

Gambar 2. Peta Lintasan Daerah Penelitian.

Struktur bawah permukaan bumi atau struktur geologi suatu daerah dapat diperkirakan menggunakan metode geofisika. Metode geofisika merupakan metode untuk mengetahui kondisi di bawah permukaan bumi yang melibatkan pengukuran di atas permukaan bumi dari parameter-parameter fisika yang dimiliki oleh batuan di dalam bumi. Metode geomagnet 
merupakan metode geofisika yang bersifat pasif, karena pengukuran dilakukan dengan cara memanfaatkan medan alami yang dihasilkan oleh bumi. Eksplorasi anomali magnetik bumi berasal dari kandungan magnetik batuan penyusunnya yang ada di bawah permukaan bumi. Kandungan magnetik tersebut dapat berasal dari suseptibulitas magnetik atau magnetik remanent. Adanya kandungan magnetik tersebut diakibatkan oleh perubahan struktur geologi bawah permukaannya atau perbedaan kandungan magnetik batuan dekat permukaan sehingga anomali magnetik bisa terlihat.

Dalam eksplorasi geomagnet, bumi dianggap sebagai penghasil medan magnet utama, sedangkan medan magnet yang sebagian kecil dihasilkan oleh kerak bumi. Jika pada daerah tertentu terlihat medan magnet, maka hal ini yang disebut dengan anomali magnetik yang dipengaruhi oleh suseptibilitas batuan. Dengan diketahuinya anomali magnetik batuan atau lapisan suatu permukaan bumi, maka dapat diketahui struktur bawah permukaan atau struktur geologi suatu daerah, jenis batuan penyusunnya, dan sumber daya alam yang terdapat dalam lapisan tersebut.Data yang diperoleh pada eksplorasi magnetik ini menunjukan sifat residual yang kompleks. Pengukuran intensitas medan magnetik bisa dilakukan melalui darat, laut, dan udara.

Pada prinsipnya, dalam penyelidikan magnet selalu dianggap bahwa kemagnetan batuan yang memberikan respon terhadap pengukuran magnet hanya disebabkan oleh pengaruh kemagnetan induksi. Dengan demikian, sifat kemagnetan ini dipergunakan sebagai dasar dalam penyelidikan-penyelidikan magnet. Sedangkan kemagnetan sisa pada umunya seringkali diabaikan dalam penyelidikan magnet karena disamping pengaruhnya sangat kecil, juga untuk memperoleh besaran dan arah kemagnetannya harus dilakukan pengukuran di laboratorium palaeomagnetik dengan menggunakan alat khusus. Perubahan yang terjadi pada kuat medan magnet bumi adalah sangat kecil dan memerlukan waktu yang sangat lama mencapai ratusan sampai ribuan tahun. Oleh karena itu, dalam waktu penyelidikan magnet, kuat medan magnet tersebut selalu dianggap konstan. Dengan menganggap kuat medan magnet bumi $(\vec{H})$ adalah konstan, maka besarnya intensitas magnet bumi $(\vec{I})$ sematamata adalah hanya tergantung pada variasi kerentanan magnet batuan yang merefleksikan harga pengukuran magnet. Prinsip inilah yang digunakan sebagai dasar penyelidikan magnet (Telford, 1990).

\section{METODE PENELITIAN}

Metode penelitian yang digunakan dalam penelitian ini adalah jenis penelitian deskriptif analitik, yang mempunyai tujuan untuk mendapatkan gambaran struktur geologi bawah permukaan laut di daerah Laut Sulawesi dengan perkiran yang didasarkan pada peta kontur anomali magnetiknya. Data yang diperoleh dari tim PPPGL. Penelitian ini berdasarkan data suseptibilitas batuan yang diperoleh kemudian dimodelkan ke dalam peta kontur menggunakan Surfer 10 dan pemodelan 2D menggunakan bantuan software Mag2DC. Data mentah penelitian berupa file Microsoft Excel yang di dalamnya terdapat variabel-variabel seperti tanggal penelitian, waktu penelitian, field magnetik, latitude, longitude, dan koordinat yang telah dikonversi menjadi koordinat UTM. Selanjutnya data tersebut dikoreksi oleh koreksikoreksi metode magnetik untuk mendapatkan hasil anomali medan magnet yang menjadi target survei, sehingga data magnetik harus terlebih dahulu dikoreksi dari beberapa pengaruh medan magnet yang lain. Secara umum koreksi pada metode magnetik yaitu:

\section{a. Koreksi Harian}

Koreksi ini dilakukan terhadap data magnetik yang terukur untuk menghilangkan pengaruh medan magnet luar atau variasi harian.

$$
\Delta H=H_{\text {total }} \pm \Delta H_{\text {harian }}
$$

\section{b. Koreksi IGRF}

Koreksi ini dilakukan untuk menghilangkan pengaruh medan magnet bumi utama yang merupakan referensi medan magnet di suatu tempat. 


$$
\Delta H=H_{\text {total }} \pm \Delta H_{\text {harian }} \pm H_{0}
$$

Untuk mempeproleh tingkat kemagnetan batuan atau nilai suseptibilitas batuan ditentukan oleh hubungan persamaan berikut:

$$
\begin{array}{cl}
\multicolumn{1}{l}{I=k H} & \\
\text { Dimana } \mathrm{k} \quad=\text { suseptibilitas } \\
\mathrm{I} \quad=\text { Intensitas magnetik } \\
\mathrm{H} \quad=\text { kuat medan magnet bumi = } \\
0,6 \text { gauss }=6 \times 10^{-5} \mathrm{~T}=6 \times 10^{4} \mathrm{n} \mathrm{T}
\end{array}
$$

Besaran ini merupakan parameter dasar yang digunakan dalam metode geomagnetik. Harga k pada batuan semakin besar apabila dalam batuan tersebut semakin banyak dijumpai mineralmineral yang bersifat magentik. Suseptibilitas magnetik batuan merupakan harga magnet suatu batuan terhadap pegaruh magnet yang erat kaitannya dengan kandungan mineral dan oksida besi. Semakin besar kandungan mineral magnetit di dalam batuan, semakin besar harga suseptibilitas suatu batuan (Telford, 1990).

\section{HASIL DAN PEMBAHASAN}

Gambar 3 merupakan pemodelan data magnetik menjadi anomali magnetik dan agar dapat diperoleh intensitas magnet total. Pemodelan ini berupa peta kontur. Peta kontur ini dilihat berdasarkan tinggi rendahnya nilai anomali magnetik. Jika terdapat kontras nilai intensitas magnetnya dengan perubahan tinggi rendah yang drastis diperkirakan daerah tersebut daerah sesar atau zona subduksi.

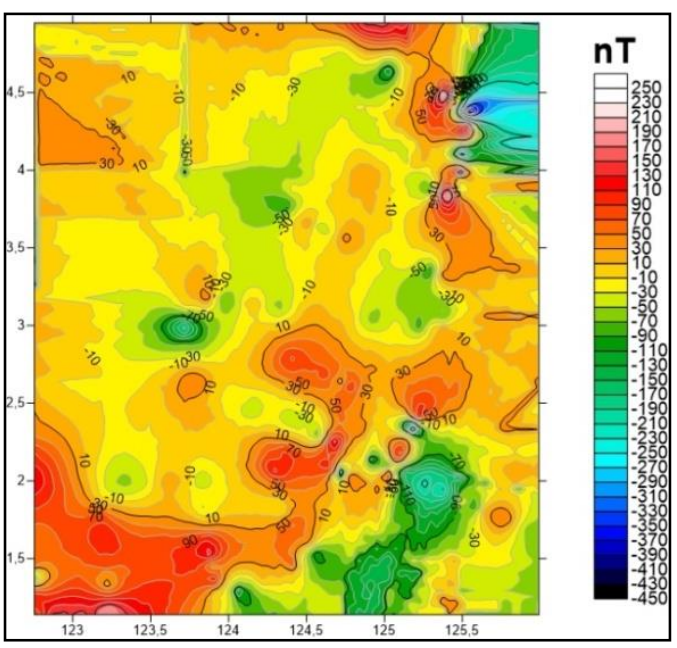

Gambar 3. Peta Kontur Anomali Magnet.

Peta kontur pada gambar 3 menunjukan bahwa warna yang memiliki notasi merah terdapat anomali tinggi yang menandakan nilai intensitas magnetnya lebih tinggi dari nilai intensitas magnet rata-rata. Anomali yang tinggi ini menunjukkan letak dari benda penyebab anomali berada tepat di bawah respon anomalinya dan memiliki sifat kemagnetan yang berbeda dengan sekitarnya (lebih tinggi) sehingga medan magnet yang dipancarkannya besar. Warna yang memiliki notasi biru menunjukan adanya anomali yang semakin rendah yang menandakan nilai intensitas magnetnya lebih rendah dari nilai intensitas magnet rata-rata. Hal ini juga sama dengan adanya anomali yang tinggi, anomali rendah pun menunjukkan letak dari benda penyebab anomali berada jauh di bawah respon anomalinya dan memiliki sifat kemagnetan yang berbeda (lebih rendah) sehingga medan magnet yang dipancarkannya lebih kecil.

Warna biru tua merupakan warna yang memiliki anomali paling rendah yaitu -450 yang diduga adanya sesar yang menyebabkan perubahan sifat fisis batuan. Daerah yang memiliki nilai anomali rata-rata menunjukkan nilai anomali yang seragam dengan daerah sekitarnya sehingga medan magnet yang dipancarkannya sama dengan daerah yang lain. Sedangkan daerah yang lain kebanyakan memiliki anomali yang lumayan tinggi yaitu sekitar $30 \mathrm{nT}$ sampai dengan $70 \mathrm{nT}$. Perbedaan warna ini menunjukan 
adanya perubahan anomali magnetik yang diakibatkan oleh hadirnya batuan atau mineral pengisi sesar, rekahan, atau intrusi lava pada batuan tersebut. Adanya sesar, rekahan, atau patahan akan menimbulkan lonjakan anomali magnetik yang secara otomatis akan terjadi perubahan warna pada kontur.

Dari anomali yang ditimbulkan maka dapat diketahui batuan penyusunnya. Gambar 4 merupakan pola sebaran suseptibilitas batuan yang terdapat pada peta kontur berdasarkan nilai intensitas magnetiknya.

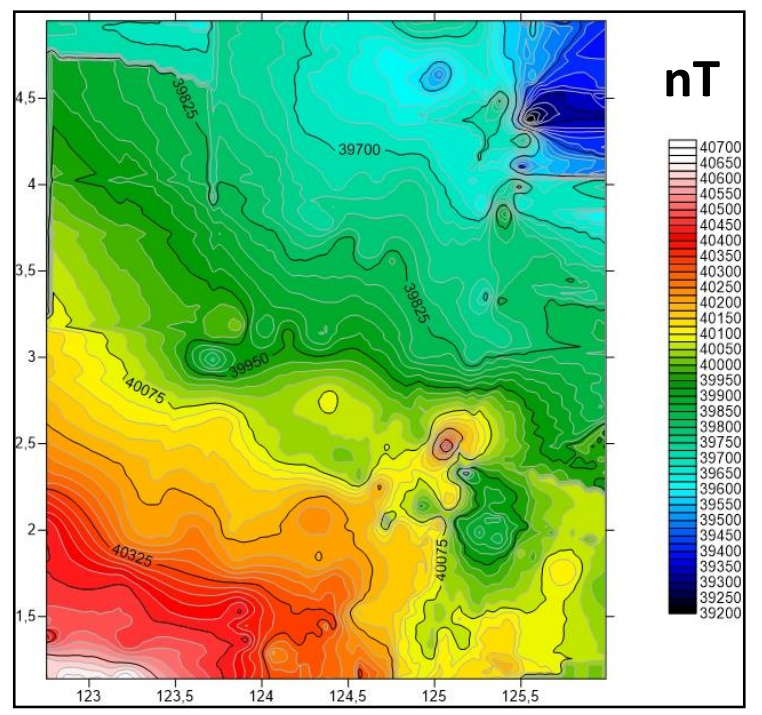

Gambar 4. Pola Intensitas Magnet Total

Perkiraan jenis batuan dihubungkan dengan nilai suseptibilitas batuan yang telah diperoleh pada masing-masing nilai intensitas magnetiknya. Pola sebaran suseptibilitas magnetik batuan tersebut dapat dibagi empat notasi warna yaitu warna putih ke merah dengan nilai suseptibilitas batuan antara 0,067833 SI sampai dengan 0,06725 SI , sedangkan yang terendah warna biru sampai hitam dengan nilai suseptibilitas antara 0,066 SI sampai dengan 0,065333 SI. Dari gambar 4.9 dan tabel 4.1 terlihat bahwa di bagian barat daya daerah penelitian sifat kemagnetan batuan relatif tinggi, sedangkan dibagian timur laut sifat kemagnetan batuannya relatif rendah. Jika mengacu pada klasifikasi tabel 1 (Telford, 1990), maka nilai suseptibilitas antara 0,067833 sampai dengan 0,065333 SI diperkirakan batuannya masuk ke dalam batuan beku jenis andesit dan basalt, dan juga terdapat batuan jenis metmorf.

Batuan andesit dan basalt ini mendominasi batuan penyusun di daerah penelitian dikarenakan daerah penelitian merupakan daerah lempeng samudera. Daerah penelitian ini merupakan bagian dari Pulau Sulawesi yang memiliki keadaan litotektonik Mandala Barat (West and North Sulawesi Volcano-Plutonic Arc) sebagai jalur magmatik (Cenozoic Volacnics and Plutonic Rock) yang

Tabel 1. Tabel skala warna pada peta pola sebaran intensitas magnet dan jenis batuannya.

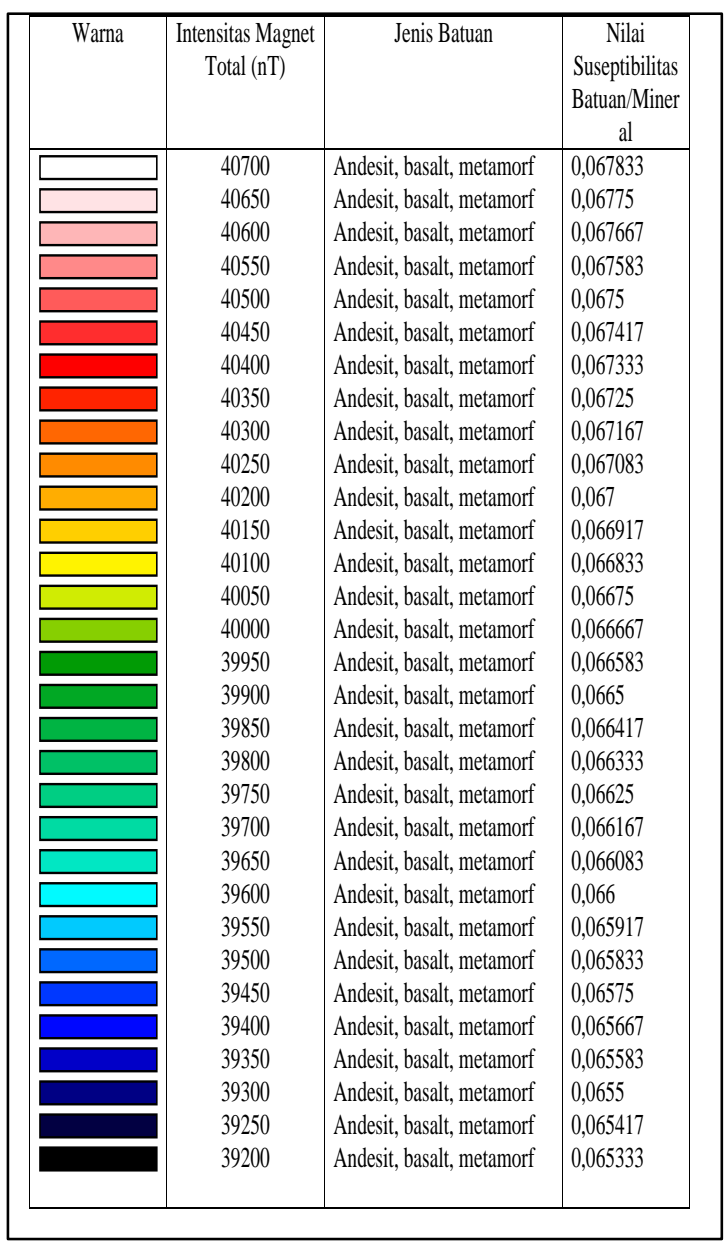


merupakan bagian ujung timur Paparan Sunda. Mandala Barat, menyebutkan bahwa mandala barat sebagai busur magmatik bagian utara yang bersifat riodasitik sampai andesitik, terbentuk pada Miosen-Resen dengan batuan dasar basaltik yang berbentuk pada Eosen-Oligosen (Van Leeuwen, 1994).

Untuk mengetahui pengaruh dan karakteristik suseptibilitas batuan terhadap struktur geologi di Laut Sulawesi dalam interpretasinya dilakukan dengan membuat model menggunakan software Mag2DC.

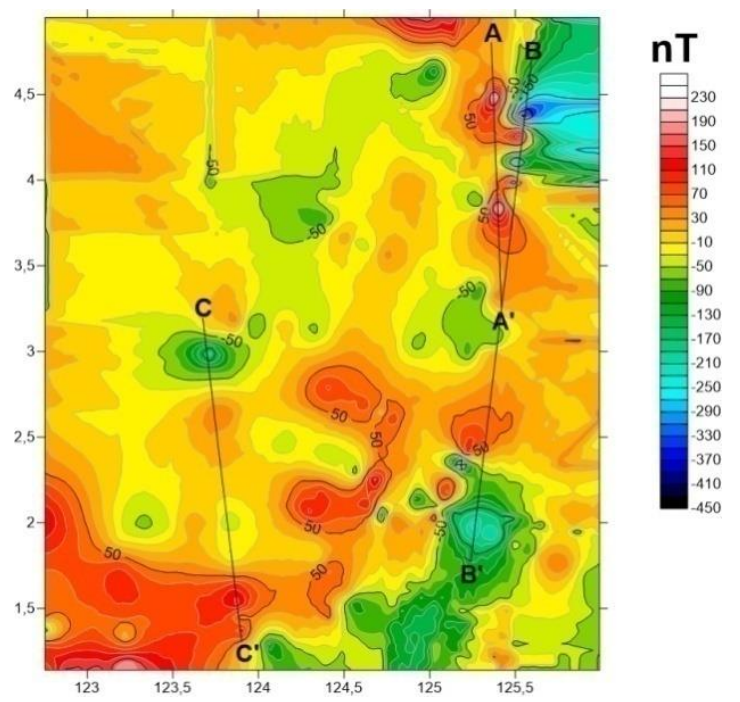

Gambar 5. Peta Kontur Anomali Magnet dengan 3 Penampang

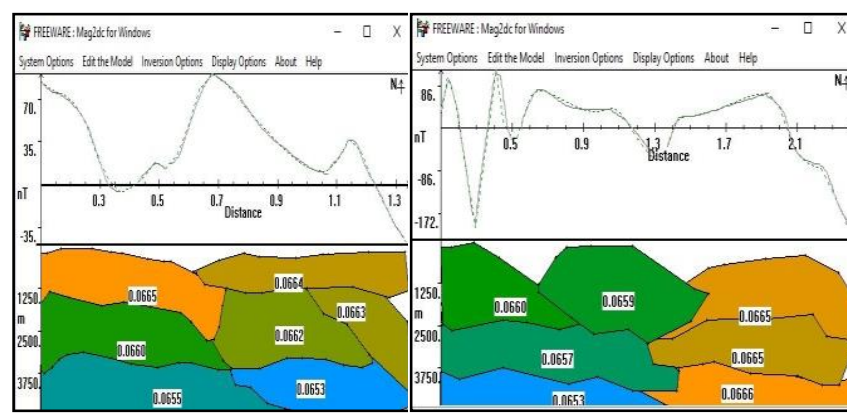

Gambar 6. Model

Penampang A-A'
Gambar 7. Model

Penampang B-B'

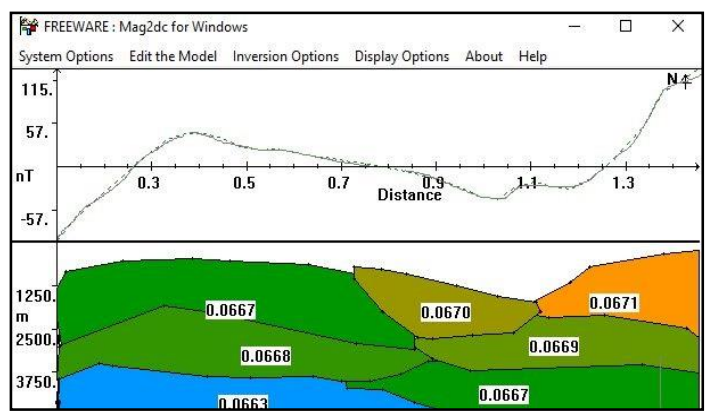

Gambar 8. Model Penampang C-C'

Hasil pemodelan yang ditunjukan oleh sayatan A-A', B-B', dan C-C' memiliki nilai suseptibilitas yang tidak jauh berbeda. Dalam kurva data magnetik dan data model terjadi penurunan dan kenaikan nilai magnetik. Ketiga sayatan didominasi oleh batuan beku jenis andesit dan basalt, dan juga batuan metamorf. Ketiga kurva sayatan ini menunjukan adanya grafik naik turun dari intensitas magnet positif sampai dengan intensitas magnet yang negatif. Adanya kurva yang naik turun ini diperkirakan adanya zona kontak litologi ataupun zona sesar.

\section{KESIMPULAN}

Berdasarkan hasil analisis pengolahan data dan interpretasi anomali intensitas medan magnet total memiliki karakteristik suseptibilitas batuan sangat berpengaruh terhadap struktur geologi di daerah Laut Sulawesi. Nilai suseptibilitas batuan sangat menentukan mineral dan batuan penyusun struktur geologi di daerah Laut Sulawesi. Menurut nilai suseptibilitasnya daerah Laut Sulawesi ini didominasi tersusun atas batuan beku andesit dan basal yang memiliki nilai suseptibilitas 0,068333 SI sampai dengan 0,065333 . Hal ini menunjukan menurut keadaan litotektoniknya daerah Laut Sulawesi ini merupakan daerah Mandala Barat sebagai busur magmatik yang batuan penyusunnya bersifat andesitik dan basaltik. Adanya nilai anomali yang kontras antara positif dan negatif pada peta kontur anomali medan magnet total sehingga adanya pengaruh geologi yang dihasilkan yaitu berupa daerah penunjaman dan terdapat patahan atau sesar.

\section{UCAPAN TERIMA KASIH}

Penulis mengucapkan terimakasih kepada Pusat Penelitian dan Pengembangan Geologi Kelautan 
(PPPGL) yang telah memberikan kesempatan kepada penulis untuk menyelesaikan penelitian ini.

\section{DAFTAR PUSTAKA}

Effendi, B. 1997. Peta Geologi Lembar Manado, skala 1:250.000. Pusat Penelitian Dan Pengembangan Geologi, Bandung.

Hamilton, W.B. 1979. Tectonic of Indonesian Region. Denver, US.S Govern. Printing office, 345 p. $159-195$.

Heryanto, S. T., Ardi N. D., dan Ilahude D. 2015. Identifikasi Struktur Geologi Bawah Permukaan Dasar Laut Berdasarkan Interpretasi Data Anomali Magnetik di Perairan Teluk Tolo Sulawesi. Fibusi (Jurnal Online Fisika), 3 (2), hlm. 1 - 7.

Illahude, D., dan Muslim, D. 2014. Identifikasi Cekungan dari Pola Anomali Magnet Total dan Nilai Suseptibilitas dari Batuan Dasar di Perairan Teluk Bone Sulawesi Selatan. Seminar Nasional Fakultas Teknologi, hlm. 324 - 333. Bandung.

Kaharrudin, M. S., Hutagalung R., dan Nurhamdan. 2011. Perkembangan Tektonik dan Implikasinya Terhadap Potensi Gempa dan Tsunami di Kawasan Pulau Sulawesi. Proceedings JCM Makassar, hlm. 1 - 10.

Koperberg, R. 1928. Bouwstoffen Voor de Geologie Van de Residentie Menado and Atlas. Jaarb. Minjwezen in Ned. Verb. 1st Ged.

Lawless, J. 1995. Guidebook: An Introduction to Geothermal System. Short course. Unocal Ltd. Jakarta.

Lita, F. 2012. Identifikasi Anomali Magnetik di Daerah Prospek Panasbumi Arjuna Welirang, Skripsi, Fakultas Matematika dan Ilmu Pengetahuan Alam, Jurusan Fisika. Depok: Universitas Indonesia.

Moechtar, H., Pratomo, I., Mulyana, H., dan Poedjoprajitno, S. 2007. Gerakan Struktur dan Kaitannya dengan Faktor Kendali Tektonik, Berdasarkan Analisis Stratigrafi: Studi Kasus Geologi Kuarter Terhadap Fase Perkembangan Danau Tondano Purba Sepanjang Remboken - Kakas, Kec. Remboken dan Kec. Kakas, Kab. Tomohon, Sulawesi Utara. Jurnal Geologi Indonesia, 2(3), hlm. $177-190$.
Mudin, Y., Yansah A., Efendi R., dan Abdullah. 2013. Estimasi Sebaran Suseptibilitas Batuan Permukaan Menggunakan Geostatistik di Kecamatan Lore Peore. Gravitasi, 15(1), hlm. 1 - 6 .

Nugraha, T. 2015. Analisis Model Data Anomali Magnetik untuk Mengidentifikasi Struktur Geologi Dasar Laut Perairan Flores. Skripsi. Fakultas Pendidikan Matematika dan Ilmu Pengetahuan Alam, Jurusan Fisika. Bandung: Universitas Pendidikan Indonesia.

Pasau, G., dan Tanauma, A. Pemodelan Sumber Gempa di Wilayah Sulawesi Utara Sebagai Upaya Mitigasi Bencana Gempa Bumi. Jurnal Ilmiah Sains, 11(2), hlm. 202 - 209.

Poedjoprajitno, S. 2009. Evolusi Bentuklahan Daerah Manado dan Sekitarnya, Sulawesi Utara. Jurnal Geologi Indonesia, 4(2), hlm. $145-155$.

Rachmat, B., dan Ilahude, D. 2011. Pola Anomali Magnet dan Nilai Suceptibilitas dari Batuan Dasar pada Pemetaan Geologi dan Geofisika di Perairan Teluk Bone Sulawesi Selatan. Jurnal Geologi Kelautan, 9(13), hlm. 13 - 22. Puslitbang Geologi Kelautan, Bandung.

Rachmawiana, A. M., Suharno, dan Rustandi. 2010. Pemodelan 3D Magnetik Menggunakan Mag3d untuk Identifikasi Sebaran Bijih BesidDi Daerah "RAMUNILA". 1 - 8.

Rongkonusa, M., Tamuntuan G., dan Pasau G. 2017. Analisis Anisotropi Suseptibilitas Magnetik Batuan Beku Lengan Utara Sulawesi. Jurnal MIPA Online, 6(1), hlm. 8 -12 .

Sehah, R. S. A., dan Prasetyo, C. A. 2015. Interpretasi Model Anomali Magnetik Bawah Permukaan di Area Pertambangan Emas Rakyat Desa Cihonje, Kecamatan Gumelar, Kabupaten Banyumas. Berkala Fisika, 18 (2), hlm. 51 - 58.

Simandjuntak, T.O. 1992. An Outline of Tectonics of The Indonesian Region. Geological News Letter. Bandung: Geological Research and Development Center.

Singarimbun, A., Bujung, C. A. N., dan Fatihin, R. C. 2011. Penentuan Struktur Bawah Permukaan Area Panas Bumi Patuha 
dengan Menggunakan Metoda Magnetik. Jurnal matematika \& sains, 18(2), hlm. 39 -48 .

Telford, W. M. 1990. Applied Geophysics Second Edition. Press Syndicate, Cambridge University.

Tim PPPGL. 2016. Penelitian Lingkungan Geologi Kelautan Dalam Rangka Mewujudkan Pengembangan Sumberdaya Energi Dan Mineral Kelautan Yang Berkelanjutan Di Perairan Laut Sulawesi. Pusat Penelitian dan Pengembangan Geologi Kelautan No.01.

Van, L. T. M. 1994. 25 Years of Mineral Exploration and Discovery in Indonesia. Journal of Geochemical Exploration, 50, hlm. $13-90$.

Widiyantoro, S., dan Van der Hilst R. 1996. Structure and Evolution of Lithosperic Slab Beneath The Sunda Arc, Indonesia. Science 271 (5255), hlm. 1566 - 1570.

Widiyantoro, S., dan Van der Hilst R. 1997. Mantle Structure Beneath Indonesia Inferred from High-Resolution Tomographic Imaging. Geophysical Journal International, 130 (1), hlm. 167 182. 